\title{
Medical equipment classification according to corrective maintenance data: a strategy based on the equipment age
}

\author{
Natália Ferreira Oshiyama, Ana Carolina Silveira, Rosana Almada Bassani, José Wilson Magalhães Bassani*
}

\begin{abstract}
Introduction: Decision-making on medical equipment management is a daily task for clinical engineers, but it may prove difficult to easily extract relevant information from the large amount of data from computerized maintenance management systems. This article describes a simple method of medical equipment classification based on corrective maintenance indicators. Methods: Three indicators were calculated based on the number of events, duration and cost of corrective maintenance. Three classes were defined according to the indicator values of different equipment ages: class A for 0-4 years, class B for 5-9 years, and class C for equipment older than 10 years. The method was applied to 2,134 pieces of equipment from the Health Service system of the University of Campinas. Results: From the total, $51.7 \%$ of the equipment were classified as C, $4.2 \%$ as B and $44.1 \%$ as A. The infusion pump for general use was the type of equipment of which most units were in the $\mathrm{C}$ class $(84.7 \%$ ), even though almost $50 \%$ of them were acquired within less than 9 years, and would thus be expected to be classified as A and B. Among the pumps in class C, 39.5\% were from a single manufacturer, although the equipments were acquired recently. Conclusion: The developed classification may be an important tool for raising alerts about equipment more prone to maintenance problems, as well as for identification of equipments with acceptable maintenance history, supporting decision-making on equipment replacement.
\end{abstract}

Keywords Clinical engineering, Database, Indicators, Medical equipment classification, Decision-making.

\section{Introduction}

The healthcare system has become dependent on new technologies developed to facilitate patient care. According to data from the World Health Organization, US\$ 8,233 were spent per capita on health in the USA in 2010 (World ..., 2013), of which it is estimated that approximately US\$ 412 were destined to medical equipment, assuming that the latter sum corresponds to $5-6.2 \%$ of the total health expenditure (Pammolli et al., 2005). The importance and considerable cost of medical devices emphasize the need of effective technology management toward diminishing costs, while augmenting quality, efficiency and safety of the services provided (Bronzino, 1992).

A good management practice includes planning, acquisition, incoming inspection, inventory, installation, commissioning and acceptance, training of users and operators, monitoring of use and performance, maintenance, and replacement or disposal of equipment. Thus, collecting information on the equipment performance and maintenance constitutes a good basis for planning new acquisitions (Cheng and Dyro, 2004). This can be done by accessing the equipment history, usually found in the databases of computerized maintenance management systems (CMMS) available in most healthcare systems (Cohen and Cram, 2004).
Yet, due to the large amount of stored data, relevant information may not be readily accessible.

Classification may be a useful tool in data analysis. In order to classify items, it is necessary to establish some criteria to identify groups (classes) with similar elements. Once the classes are defined, the items can be classified according to the description of the attributes of each class (Hastie et al., 2009). In this study, equipment age was chosen as the criterion for establishment of classes because, with constant use, replacement of parts tends to occur more often, and preventive maintenance may be required more frequently. This is an important criterion, since equipment reaches a point in its life-cycle at which frequent failure leads to greater downtime and diminished cost-benefit ratio (Clark, 2004). It was hypothesized, therefore, that corrective maintenance data (i.e., frequency, duration and cost of services, which can be easily extracted from the database) would provide suitable indicators for the establishment of age-based classes, on the assumption that older equipment usually fails more often than recently acquired ones. Equipment was then divided into three classes (A, B and C), in which the best maintenance performance, compatible to that of newly-acquired equipment, characterizes class $\mathrm{A}$, and the poorest 
performance characterizes class $\mathrm{C}$. This medical equipment classification can help clinical engineers identify the need for equipment replacement and manufacturer-dependent frequent equipment failure, as well as the need of training of the maintenance group or users.

\section{Methods}

A database (Microsoft Excel ${ }^{\mathrm{TM}}$ spreadsheet) containing information on the equipment (identification number, location of use, manufacturer, model, acquisition date and cost of acquisition) and corrective maintenance data (number of events, total time and total cost) was produced with data from the CMMS of the Center for Biomedical Engineering of the University of Campinas, which is responsible for the maintenance of the medical equipment of the university's healthcare area. The data used in this study were collected from 2004 to 2009.

From the corrective maintenance data, three primary indicators were calculated: number of corrective maintenance events $(N M)$, total time spent on corrective maintenances $(T M)$ and corrective maintenance cost $(C M)$, as follows.

$$
\begin{aligned}
& N M_{i}=\frac{\text { Annual }(\text { Number })_{i}}{\text { median }\left(\text { Number }_{\text {total }}\right)} \\
& T M_{i}=\frac{\text { Annual }(\text { Time })_{i}}{{\text { median }\left(\text { Time }_{\text {total }}\right)} \text { ) }} \\
& C M_{i}=\frac{\text { Annual }(\text { Cost })_{i}}{0.06 \times(\text { Acquisition_Cost })}
\end{aligned}
$$

The index $i$ corresponds to the individual equipment analyzed $(I=1,2, \ldots, n)$, for a total of $n$ equipments. In order to calculate the indicator $N M$, the number of maintenance events for a given item was considered as the annual average of the six years (Annual(Number) $)_{i}$ ). This value was then divided by the median of the annual number of corrective maintenances performed by the same maintenance group for all the equipments in the database (Number ${ }_{\text {total }}$ ). The latter step makes it possible to compare the indicator values obtained from different maintenance groups, which, however, was not the case here. The same was done to calculate the indicator for total time of maintenance (TM). The cost $(C M)$ was calculated by dividing the average annual cost of corrective maintenance (Annual(Cost)) by 6\% of the equipment acquisition cost. This percentage is within the expected range of expenditure with corrective maintenance (3-15\% of the acquisition cost; Cruz et al., 2002) and was calculated by the straight-line depreciation method (Albrecht et al., 2010) assuming a minimum equipment lifetime of
15 years. Because the age range of the equipment in this study was $0-14$ years, the maximum depreciation would be $6.7 \%$ per year.

It has been accepted that, as the equipment gets older, failures become more frequent, which increases the downtime and the cost of the corrective maintenance (Bronzino, 1992; Dondelinger, 2003, 2004). Since this is an intrinsic characteristic of equipment in the general, it was assumed that age would be a good parameter for establishing limits for the calculation and identification of the maintenance profile. Three classes were then defined according to the profile of equipment of different age ranges: A (0-4 years), B (5-9 years) and $\mathrm{C}$ ( $>10$ years). The profile was characterized by the means $(\overline{N M}, \overline{T M}, \overline{C M})$ and respective standard error $(S E M)$ values of the indicators for the three age ranges, i.e., $(\overline{N M} \pm S E M, \overline{T M} \pm S E M, \overline{C M} \pm S E M)_{j}$, where $j$ corresponds to one of the three age ranges.

The indicators were compared among classes with one-way analysis of variance. As it can be seen in Figure 1, and further explained in the Results section, the initial assumption was supported by the observation that the values of the indicators significantly increased with the equipment age,

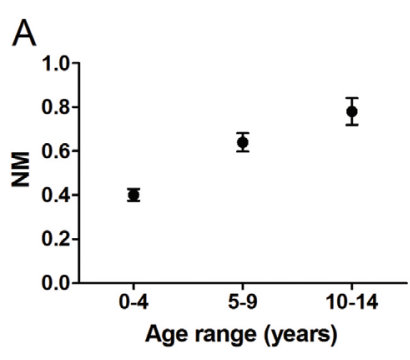

B
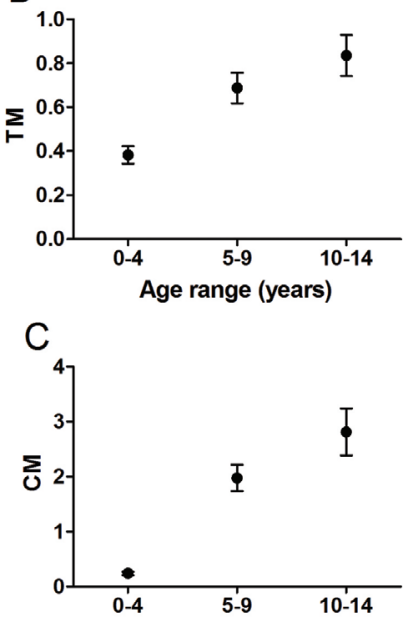

Figure 1. Mean values and standard error for each equipment age range of the corrective maintenances indicators: number of events (NM, panel A), total time under maintenance (TM, panel B), and for maintenance cost (CM, panel C). 
indicating that the maintenance performance was the best in class A and the worst in class $\mathrm{C}$.

As the standard behavior of the whole equipment population was identified, individual pieces of equipment could be classified according to the values of their indicators and the ranges defined by the mean \pm SEM of each class. If, however, the value of an indicator was between the range limits of two classes, the equipment was considered to belong to the class to which the equipment's indicator value had greater proximity. Classification was determined for each of the 3 indicators. The equipment was classified as $\mathrm{C}$ if at least one of its maintenance indicators were compatible with the $\mathrm{C}$ class. On the other hand, the condition for the equipment to be classified as A was that all the 3 indicators were compatible with the A class. In all other cases, the equipment was classified as B. An example of the spreadsheet with the classification of individual indicators and the final equipment classification is shown in Table 1.

By filtering a particular entry from the spreadsheet (e.g. equipment type, model, age, manufacturer, location of use), scores of each individual piece of equipment may be available for post-hoc analysis, allowing the clinical engineer to search for specific reasons for possibly unexpected results, e.g. score $\mathrm{C}$ for most of the items of a recently acquired batch of devices. The apparently "poor maintenance performance" indicated by this score might be due to several factors that would require further investigation. As the number of equipment in the database grows, robustness of the analysis increases, as it would be the limit case of large healthcare conglomerates or a nation-wide system.

\section{Results}

As shown in Figure 1, a significant difference between the age ranges was observed for all corrective maintenance indicators calculated. The NM values for classes A, B and C were, respectively, $0.40 \pm 0.03$, $0.64 \pm 0.04$ and $0.78 \pm 0.06(\mathrm{~F}=21.25$; degrees of freedom $=391, \mathrm{p}<0.001)$. The values of the TM indicator were $0.38 \pm 0.04,0.69 \pm 0.07$ and $0.83 \pm 0.09$ for classes $\mathrm{A}, \mathrm{B}$ and $\mathrm{C}$, respectively $(\mathrm{F}=12.51$; $\mathrm{p}<0.001$ ), while for $\mathrm{CM}$, the mean values were $0.24 \pm 0.03$ for class $\mathrm{A}, 1.97 \pm 0.24$ for class $\mathrm{B}$ and $2.81 \pm 0.42$ for class $\mathrm{C}(\mathrm{F}=31.03 ; \mathrm{p}<0.001)$. These results support the initial assumption of a positive relationship between equipment age and the occurrence of corrective maintenance problems.

From the total of 2134 equipment, $51.7 \%$ were classified as C, $4.2 \%$ as B and $44.1 \%$ as $\mathrm{A}$. The elevated number of medical devices classified as $\mathrm{C}$ should raise alerts for further investigation, which was carried on, in this case, by the detailed analysis of four equipment types: 123 physiological monitors, 84 general use infusion pumps, 77 pulmonary ventilators, and 50 syringe infusion pumps. These types of equipment are usually located at intensive care units and operating rooms, and they are considered as high-risk devices because their failure might have marked impact on the patients' well-being (Melendez and Rane, 2004; Miodownik, 2004).

Among all equipment, the general use infusion pumps were the type with more items classified as C (84.7\%). Pulmonary ventilators also showed a considerable trend to come under class C: 57 out of 77 units (74\%) (Figure 2).

Even though almost $50 \%$ of the general use infusion pumps and pulmonary ventilators were 0-9 year-old (Figure 2B), and would thus be expected to come under classes $\mathrm{A}$ and $\mathrm{B}$, only $15.3 \%$ of the pumps and $23 \%$ of the ventilators were classified as such (Figure 2A). This means that not always does new equipment need less corrective maintenances, as well as that equipment classified as $\mathrm{C}$ may have the maintenance profile similar to that of recently acquired devices. This becomes more evident from the analysis of general use infusion pumps: for instance, all devices from manufacturer M54 were in the age range of $0-9$ years, yet $83.3 \%$ were classified as $\mathrm{C}$ (Figure 3). This observation points out a specific problem concerning equipment from this manufacturer, which may be due to the equipment itself, to problems in its usage and/or its maintenance.

\section{Discussion}

The method developed in this study for the classification of medical equipment is simple and can be easily implemented. It is only necessary to have the corrective maintenance data from a CMMS and a program that allows the preparation of spreadsheets, such as Microsoft Excel ${ }^{\mathrm{TM}}$. In developing countries, it is common the existence of medical equipment with age greater than 10 years, which would be expected to fail more frequently. In this case, the availability of an equipment classification tool to facilitate management becomes especially valuable.

In the present method, once the equipment classes are established based on the average age, any particular device of the same equipment pool is again checked against the value ranges of the indicators for its individual classification. This means that it may happen that an old piece of equipment can be classified as A and a new one as $\mathrm{C}$. The greater the equipment pool 


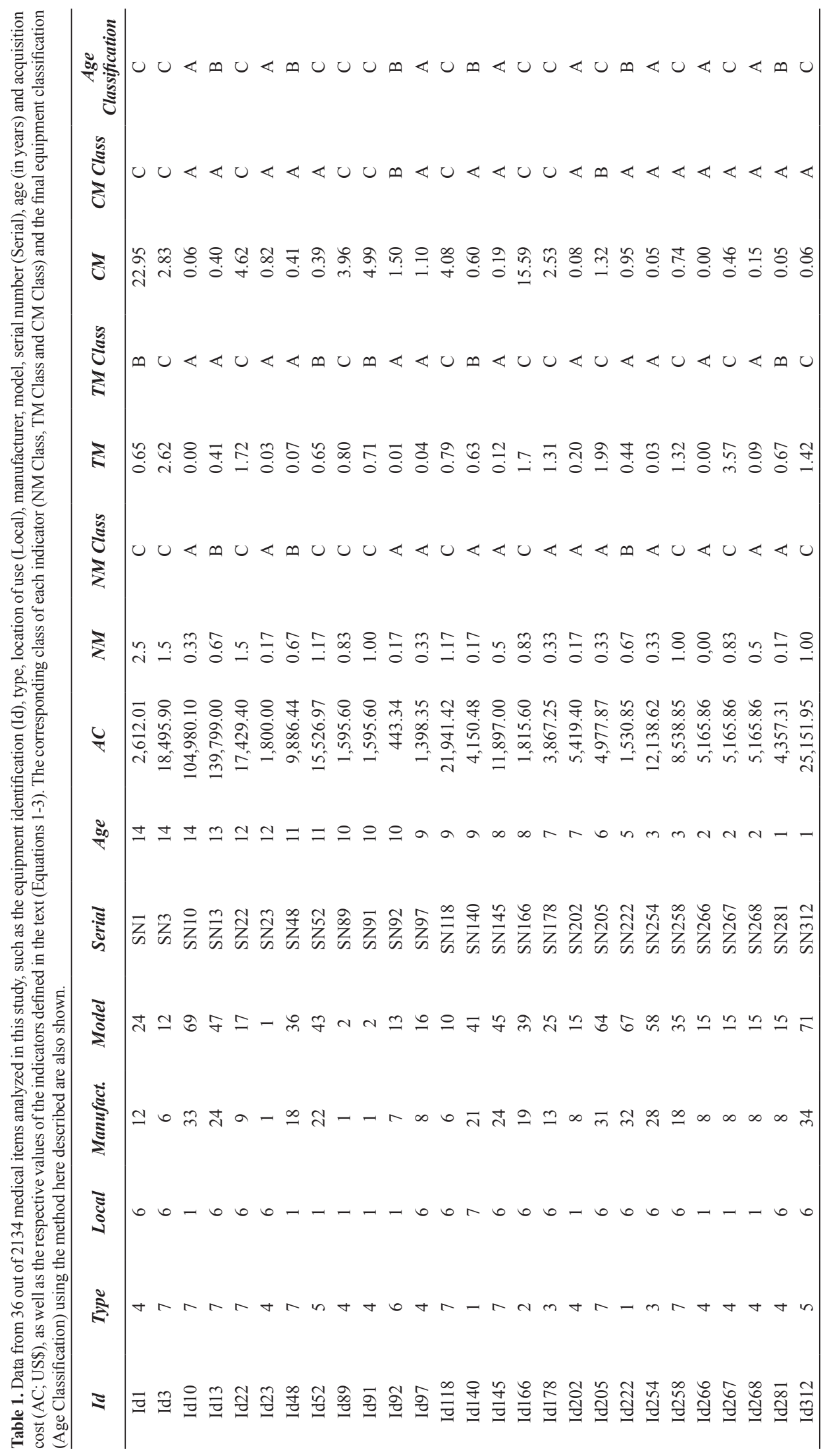



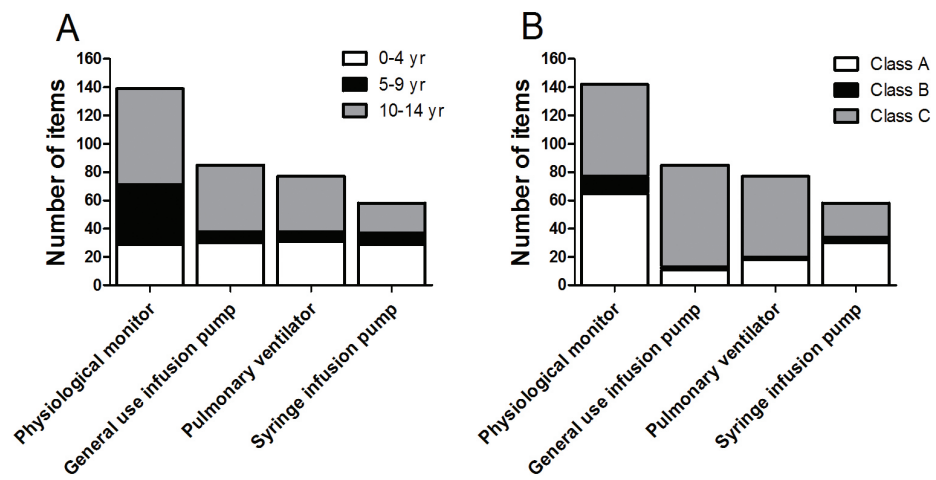

Figure 2. Number of items of four types of high-risk medical equipment in each age range (A) and in each class according to their corrective maintenance performance (B).

A

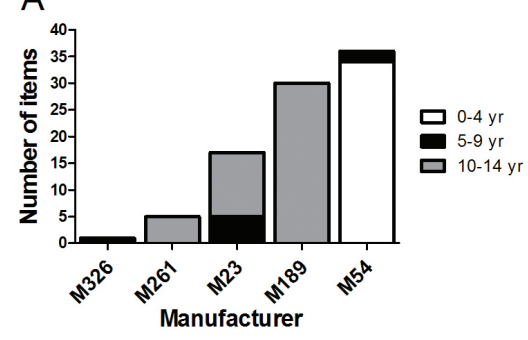

B

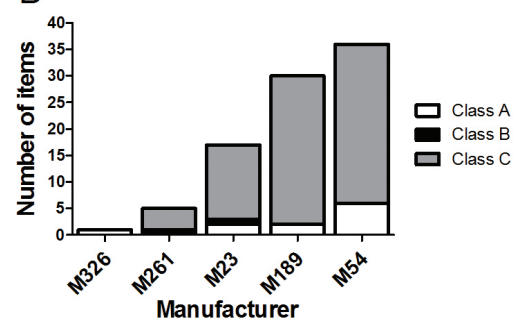

Figure 3. Number of general use infusion pumps from five manufacturers categorized according to the equipment age (A) and to the classification according to the corrective maintenance performance (B).

used to establish the classes, the more robust is the classification.

With the classification results, many post-hoc analyses could be made by the professionals responsible for technology management. The four types of equipment further investigated in the present study were chosen due to the high percent of items classified as C. General use infusion pumps are important life support devices used for therapeutic and/or diagnosis purposes, but also carry considerable risk in the case of malfunction, as infusion rates different from those prescribed may be even lethal (Association..., 2010). Another reason to focus on this type of equipment is the observation of a typically high number of nonprogrammed service orders, i.e., corrective maintenance (Taghipour et al., 2010). When the manufacturers were compared, M54 was identified as one of the sources of a large percent of the pumps classified as C (39.5\%), even though $94 \%$ of the equipment from this manufacturer was 0-4 year-old. Possible reasons for this atypical maintenance behavior might involve the equipment design, parts and/or assembly, as well as the clinical and maintenance teams.

It is important to identify individual devices or equipment (and their manufacturers) most prone to failure because they represent poor investment over time, and medical technology managers should have quantitative data to justify the need to replace the equipment. But the equipment per se might not be the only possible cause of failure: error in the equipment use by the clinical staff and/or lack of adequate maintenance by the clinical engineering group may contribute to it. In the method presented here, the classification according to the corrective maintenance data raises an alert for further investigation of the possible causes of a maintenance performance not compatible with that expected for the equipment age. Depending on how the information in the spreadsheet is filtered, the main cause of the poor classification could be identified. For instance, if there is a type of equipment of a given age range and from a certain manufacturer that is classified as $\mathrm{C}$ only at one place of use, this filtering could indicate the necessity of better user training.

It should be stressed that the age-based classification presented here should not be used as the sole tool for support of administrative or regulatory decisions, but rather as source of alert for the clinical engineering and administrative teams on critical aspects that require more detailed investigation. Additional information may be necessary for a correct and robust decision (Oshiyama et al., 2012). In the daily, routine use, as it should be the case for all types of indicators, clinical engineers should monitor and investigate 
each aspect, aiming at improving equipment choice and service delivery, as well as adequately training of the health care staff. If used in hospitals nationwide, this classification might even help raising flags for regulatory agencies, since these indicators are expected to be independent of the size of the hospital or the size and quality of the maintenance groups.

\section{Acknowledgements}

Authors are indebted to the Clinical Engineering and Informatics teams from the Center for Biomedical Engineering of the University of Campinas for their invaluable assistance during collection and analysis of equipment data. Financial support: Conselho Nacional de Desenvolvimento Científico e Tecnológico (SAE/ UNICAMP, CNPq, Grant. N. 831346/1988-4, NFO, Grant. N. 300632/2005-3, JWMB).

\section{References}

Association for the Advancement of Medical Instrumentation - AAMI. Infusing patients safely. Priority issues from the AAMI/FDA infusion device summit. Arlington: AAMI; 2010. 41 p.

Albrecht WS, Stice EK, Stice JD. Financial accounting. Ohio: Cengage Learning; 2010.

Bronzino JD. Management of medical technology - a primer for clinical engineers. Boston: Butterworth-Heinemann; 1992. PMid:1596745.

Cheng M, Dyro JF. Good management practice for medical equipment. In: Dyro JF, editor. Clinical engineering handbook. Burlington: Elsevier Academic Press; 2004. p. 108-10. http:// dx.doi.org/10.1016/B978-012226570-9/50035-1

Clark TJ. Health care technology replacement planning. In: Dyro JF, editor. Clinical engineering handbook. Burlington: Elsevier Academic Press; 2004. p. 153-4. http://dx.doi. org/10.1016/B978-012226570-9/50046-6

Cohen T, Cram N. Computerized maintenance management systems. In: Dyro JF, editor. Clinical engineering handbook. Burlington: Elsevier Academic Press; 2004. p. 124-30.
PMid:15316975. http://dx.doi.org/10.1016/B978-0122265709/50040-5

Cruz AM, Denis ER, Villar MCS, Lic GLM. An eventtree-based mathematical formula for the removal of biomedical equipment from a hospital inventory. Journal of Clinical Engineering, 2002; 27(1):63-71. http://dx.doi. org/10.1097/00004669-200202710-00039

Dondelinger RM. A simple method of equipment replacement planning. Biomedical Instrumentation \& Technology, 2003; 37(6):433-6.

Dondelinger RM. A complex method of equipment replacement planning. Biomedical Instrumentation \& Technology, 2004; 38(1):26-31. http://dx.doi. org/10.2345/0899-8205(2004)38[26:ACMOER]2.0.CO;2

Hastie T, Tibshirani R, Friedman J. The elements of statistical learning: data mining, inference and prediction. New York: Springer; 2009. http://dx.doi.org/10.1007/978-0-387-84858-7

Melendez L, Rane R. Anesthesiology. In: Dyro JF, editor. Clinical engineering handbook. Burlington: Elsevier Academic Press; 2004. p. 384-91. http://dx.doi.org/10.1016/ B978-012226570-9/50099-5

Miodownik S. Operating room. In: Dyro JF, editor. Clinical engineering handbook. Burlington: Elsevier Academic Press; 2004. p. 376-84.

Oshiyama NF, Bassani RA, D’Ottaviano IML, Bassani JWM. Medical equipment classification: method and decision-making support based on paraconsistent annotated logic. Medical \& Biological Engineering \& Computing, 2012; 50(4):395-402. PMid:22407498. http:// dx.doi.org/10.1007/s11517-012-0888-6

Pammolli F, Riccaboni M, Oglialoro C, Magazzini L, Baio G, Salerno N. Medical devices competitiveness and impact on public health expenditure. Luxembourg: Office for Official Publication of the European Communities; 2005.

Taghipour S, Banjevic D, Jardine AKS. Reliability analysis of maintenance data for complex medical devices. Quality and Reliability Engineering International. 2010; 27(1):7184. http://dx.doi.org/10.1002/qre.1084

World Health Organization - WHO. World Health Statistics 2013 [internet]. 2013 [cited 2013 June 08]. Available from: http://www.who.int/gho/publications/ world health statistics/2013/en/.

\footnotetext{
Authors

Natália Ferreira Oshiyama, Ana Carolina Silveira, José Wilson Magalhães Bassani*

Departamento de Engenharia Biomédica, Faculdade de Engenharia Elétrica e de Computação, Universidade Estadual de Campinas - UNICAMP, Rua Alexander Fleming, 105, Cidade Universitária Zeferino Vaz, CEP 13083-881, Campinas, SP, Brasil.
}

Rosana Almada Bassani, José Wilson Magalhães Bassani

Centro de Engenharia Biomédica, Universidade Estadual de Campinas - UNICAMP, Campinas, SP, Brasil. 